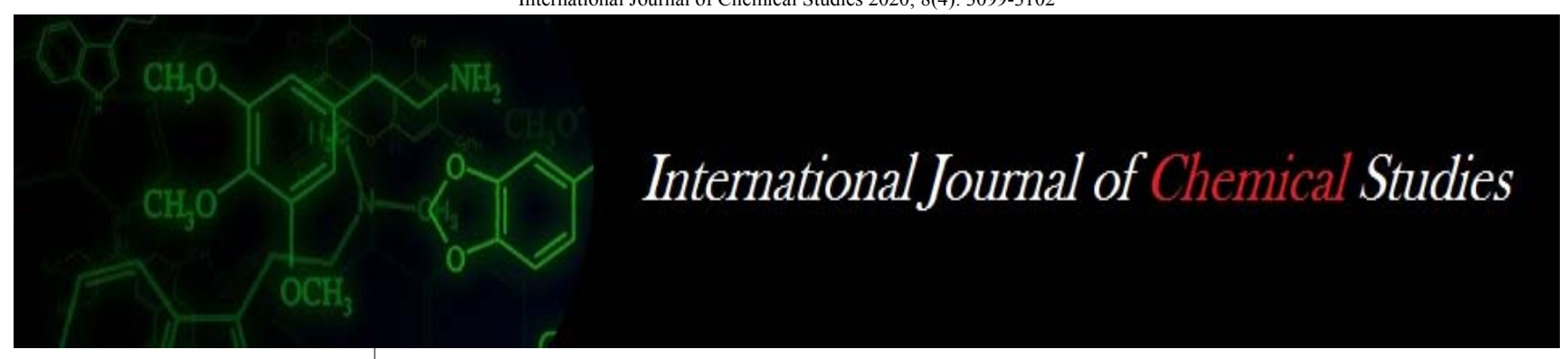

P-ISSN: 2349-8528 E-ISSN: 2321-4902 www.chemijournal.com IJCS 2020; 8(4): 3099-3102 (C) 2020 IJCS

Received: 16-05-2020 Accepted: 18-06-2020

Vijay Pandurang Kapale Department of Biochemistry, ICAR-G.B. Pant University of Agriculture and Technology, Pantnagar, Uttarakhand, India

\section{Chenesh Patel}

Department of Entomology, ICAR- G.B. Pant University of Agriculture and Technology, Pantnagar, Uttarakhand, India

\section{RM Srivastava}

Department of Entomology, ICAR-G.B. Pant University of Agriculture and Technology, Pantnagar, Uttarakhand, India

Sanjeev Agrawal Department of Biochemistry, ICAR-G.B. Pant University of Agriculture and Technology, Pantnagar, Uttarakhand, India

Corresponding Author: Vijay Pandurang Kapale Department of Biochemistry, ICAR-G.B. Pant University of Agriculture and Technology, Pantnagar, Uttarakhand, India

\section{Defense Traits and Tolerance Strategies of Plants against Herbivores}

\author{
Vijay Pandurang Kapale, Chenesh Patel, RM Srivastava and Sanjeev \\ Agrawal
}

DOI: https://doi.org/10.22271/chemi.2020.v8.i4al.10125

\begin{abstract}
Plants exposes to various types of biotic and abiotic stresses. It received various signals called Herbivoreassociated molecular patterns (HAMPs) and induces defence mechanism against insects. Defense system, by this plant mitigates the adverse effects of herbivore, consisting of various morphological, biochemical, and molecular mechanisms. The trichomes, epidermis, cuticle, and bark tissues are important physical barriers to herbivores. Various secondary metabolites reduces digestibility in insect. The cysteine protease overexpression in maize retard the growth of $S$. frugiperda. In Arabidopsis, release of green-leaf volatiles by overexpression of $\mathrm{hpl}$ gene increases, which increases attraction of parasitoid Cotesia glomerata that increases mortality of larva of Pieris rapae. The application of plant hormones like JA, $\mathrm{SA}$, and Ethylene etc. also induces defence system in the plant against insect. However, the exact defensive mechanism is still not understood. Studying the level of molecular mechanism of induced resistance against insect could be an important tool for the pest management.
\end{abstract}

Keywords: defense traits, tolerance strategies, plants against herbivores

\section{Introduction}

Plants face various types of biotic and abiotic stresses. Drought, salinity and heat stress are most important abiotic stresses to the plants while pathogens, bacteria and specially insects are most important biotic stress to the plant. Although, insects are small in size but they are considered as very dangerous threat to plant survival, due to their abundance, diversity and highly capable to induce insecticide tolerance in nature. Plants took millions of year to evaluate efficient defence system against insects. Many scientists are extensively studying the ecology and evolution of plant-insect interactions (Goodspeed et al., 2012) ${ }^{[1]}$. In this review we focus primarily on the major biomolecules, different genes and tolerance strategies involved in defence system against insect. These approaches are to understand biochemical and molecular mechanism of plant-insect interaction and defence system in plant against insects.

\section{Toxic Secondary Metabolites}

Plants synthesize huge number of various secondary metabolites, which reduces digestibility in insect. In Arabidopsis mutations in genes of activation and regulation of GS biosynthesis make the Arabidopsis highly susceptible to chewing type of insect. While in several insects acclimatize to GS, some level of resistance provide by the metabolites synthesized from the phenylpropanoid pathway. In Arabidopsis mutant for fah1-7 confirm high number of $P$. brassicae (Onkokesung et al., 2016) ${ }^{[2]}$. Besides, MYB75 overexpressing lines showed reduced levels of kaempferol 3,7-dirhamnoside that increases the performance $P$. brassicae (Onkokesung et al., 2014) ${ }^{[3]}$.

In mutated tobacco lines dropping nicotine content increases the performance of not only $M$. sexta, S. exigua, but also to other native herbivores. This increased performance was reduced after nicotine application (Machado et al., 2016) ${ }^{[4]}$, (Steppuhn et al., 2004) ${ }^{[5]}$. In maize mutant line for $b x 1$ reduces level of benzoxazinoids, DIMBOA-Glc and HDMBOA-Glc, as a result feeding was increased by S. exigua and S. littoralis (Maag et al., 2016) ${ }^{[6]}$. Another important secondary metabolite sesquiterpene 7 epizingiberene also involved in resistance development in plant e.g. tomato against to M. sexta (Bleeker et al., 2012) ${ }^{[7]}$. 
In Arabidopsis, mutant for diterpene rhizathalene A synthesis by terpene synthase significantly increases feeding by Bradysia sp. (Vaughan et al., 2013) ${ }^{[8]}$.

In dandelion (Taraxacum officinale), sesquiterpene lactone taraxinic acid $\beta$-D-glucopyranosyl ester formation in root latex tolerate attachment of Melolontha melolontha, whereas mutation in germacrene A synthase ToGAS1, which catalyzes sesquiterpene lactone taraxinic acid $\beta$-D-glucopyranosyl ester, enhances attractiveness to Melolontha melolontha (Huber et al., 2016) ${ }^{[9]}$.

The role of secondary metabolites against phloem-feeding insects is less clear. The aphid, one of the major pests of agriculture, has contrasting performance in a mutant altering indole GS level (Barth and Jander, 2006) ${ }^{[10]}$, (Pfalz et al., 2009) ${ }^{[11]}$. In Arabidopsis camalexin increases tolerance to aphids but its mutant for camalexin by silencing pad3 is susceptible to aphids (Kusnierczyk et al., 2008) [12]. Furthermore, callose inducibility directly regulated by benzoxazinoids which are toxic and acts against to chewing and phloem-feeding type of insects. In bx13 mutant of maize feeding by $S$. exigua, and $S$. littoralis and leaf aphid, Rhopalosiphum maidis was increased (Handrick et al., 2016) [13].

\section{Defense Proteins}

Protease inhibitors are usually efficient antiherbivore proteins in defense mechanism (Johnson et al., 1989) ${ }^{[14]}$. Further study with knockout genes in several plant species has confirmed the important role of protease inhibitor against various herbivores. The cysteine protease overexpression retard growth of S. frugiperda in maize (Pechan et al., 2002) [15].

Another efficient defense strategy against insects is the depletion of essential amino acids in insect diets. Transgenic tomato deficient in threonine deaminase (TD2), which catalyzing conversion of L-threonine into alpha-ketobutyrate and ammonia, are more vulnerable to $S$. exigua and T. ni (Gonzales-Vigil et al., 2011) ${ }^{[16]}$. Threonine deaminase inhibited by isoleucine. Interestingly, in insect midgut the proteolytic activation enhances TD efficiency (Chen et al., 2005) ${ }^{[17]}$. Similarly, N. attenuata lines deficient in threonine deaminase are more susceptible to $M$. sexta (Kang et al., 2006) ${ }^{[18]}$. Finally, in tomato overexpression of arginase drastically reduces this enzyme content in larval midgut of $M$. sexta and makes the tomato more resistant to $M$. sexta (Chen et al., 2005) ${ }^{[17]}$.

The role of defense proteins against phloem-feeding insects is less clear. In Arabidopsis Overexpression of PP2-A1, reduces $M$. persicae infestation. This might be due to clogging sieve pores (Zhang et al., 2011) ${ }^{[19]}$. Chaperone also known to plays an important role in defense system. The recently identified chaperone, SLI1, may avoid piercing of stylet into the sieve tubes. In Arabidopsis mutant deficient in SLI1 demonstrate increased feeding and infestation by M. persicae (Kloth et al., 2017) ${ }^{[20]}$.

\section{Volatiles as Attractants of Herbivore Natural Enemies}

In response to herbivores attack plants releases various volatile compounds. Some of these are known in defense system since they affect herbivores interaction and increases attraction to natural enemies of herbivores i.e. parasites. Additionally these volatiles promote plant herbivores interaction. In Arabidopsis, the overexpression of hydroperoxide lyase gene (HPL) increases the release of green-leaf volatiles, which increases attraction of parasitoid
Cotesia glomerata that increases mortality of larva of Pieris rapae (Shiojiri et al., 2006) ${ }^{[21]}$. In $N$. attenuate mutant lines deficient in HPL contains low number of egg predator Geocoris punctipes (Halitschke et al., 2008) ${ }^{[22]}$.

Silencing the marker enzyme of jasmonic acid biosynthesis (LOX2) reduces attachments of predator and increases damage by $M$. sexta (Schuman et al., 2012) ${ }^{[23]}$. The overexpress the maize terpene synthase TPS10 in Arabidopsis releases sesquiterpenes and thus Arabidopsis become more attractive to Cotesia marginiventris (Schnee et al., 2006) ${ }^{[24]}$. Jasmonic acid (JA) is well known to induce defence system against insect. In maize JA treatment induces the expression of APETALA 2 (AP2)/ERF EREB58 transcription factor which binds to TPS10 promoter and regulate the volatile sesquiterpenes production (Li et al.,2015) ${ }^{[25]}$. In rice $S$ linalool increases attraction of the parasitoid Anagrus nilaparvatae. In mutant rice in which $S$-linalool synthase was silenced reduces attraction of Anagrus nilaparvatae leading to increase in BPH (Xiao et al., 2012) ${ }^{[26]}$.

\section{Physical Barriers}

The trichomes, epidermis, cuticle, and bark tissues are important physical barriers to herbivores. On Arabidopsis lyrata mutant line for GLABROUS1, key gene regulating trichome development, high number of leaf-chewing insects occurs (Kivimäki et al., 2007) [27]. Whereas, Arabidopsis mutant line for gl1 showed more susceptibility to S. littoralis (Reymond et al., 2004) [28]. Remarkably, an Arabidopsis mutant for decreased cuticular wax and cutin shows more resistant S. littoralis (Blanc et al., 2018) ${ }^{[29]}$.

\section{Tolerance Strategies}

The capacity of plants to repair, regrow and reproduce after insect attack is known as tolerance. It varies from plant to plant and species to species. Such capacity is important for plant to survival against insects. However the chemistry of plant tolerance to herbivores still remains poorly studied. Herbivores attacked the plants and uptake the nutrients.

Herbivores attack on $N$. attenuate reduces not only the carbohydrate in roots but also the regrowth capacity of defoliated plants. The JA application on $N$. attenuate recovered the plant from above threat against insect (Machado et al., 2013) ${ }^{[30]}$. In solanaceae species that exhibit a lower JA showed the greater defoliation tolerance (Machado et al., 2017) ${ }^{[31]}$. Furthermore, in N. attenuata silencing the SnRK1 increases carbon transport to the roots and prolongs flowering, this SnRK1 silencing may positively regulate the depletion of carbohydrate root and increase tolerance (Schwachtje et al.,2006) ${ }^{[32]}$.

\section{Progress with Genomics Approaches}

Whole-genome analyses of plants infected by herbivores have produced an unbiased transcriptional profile in defense signaling pathways. Insects of the same feeding pattern showed overlapping transcriptome signatures, some of these are clearly specific to chewing larvae and phloem-feeding insects (Kusnierczyk et al., 2008) ${ }^{[12]}$; (Reymond et al., 2004) ${ }^{[28]}$. Plants, in response to herbivores attack, synthesize JA which along with functional COI1 induces expression of responsive genes (Reymond et al., 2004) ${ }^{[28]}$, (Schweizer et al., 2013) ${ }^{[33]}$.

Genetic approaches like QTL (quantitative trait locus) mapping and genome-wide association have most potential for uncovering novel molecular players in defense system. One of the novel proteins SLI1 impairs phloem ingestion 
(Kloth et al., 2017) [20]. In Arabidopsis genome-wide association study determine loci that control variation in GS profiles under biotic and abiotic stresses (Brachi et al., 2015) ${ }^{[34]}$, (Chan et al., 2011) ${ }^{[35]}$. Whole-genome analyses may prove valuable tool for discovering novel and important defense genes.

\section{Conclusion}

The continuous efforts to understand molecular mechanism of plant-herbivore interactions and responsive defense system by numbers of scientist from glob unveiled an important molecular players involved in defense system in plant against insects. Genomic approaches allow understanding the role defense genes in intricate signaling network and mechanisms of herbivore tolerance in plant.

Future challenges include how signals from insect is perceived, how it activate downward defense system in plant and how specificity is obtained against different herbivory and pathogenesis. Herbivores evaluate themselves via biochemical and behavioral adaptations against plant, which in turn plants also evaluate defense regulation and expression patterns. Understanding the molecular mechanisms of such phenomena holds the key to appreciate fully the beauty and diversity of plant-herbivore interactions.

\section{References}

1. Goodspeed D, Chehab EW, Min-Venditti A, Braam J, Covington MF. Arabidopsis synchronizes jasmonatemediated defense with insect circadian behavior. PNAS. 2012; 109:4674-4677.

2. Onkokesung N, Reichelt M, Van Doorn A, Schuurink RC, Dicke M. Differential costs of two distinct resistance mechanisms induced by different herbivore species in Arabidopsis. Plant Physiol. 2016; 170:891-906.

3. Onkokesung N, Reichelt M, Van Doorn A, Schuurink RC, Van Loon JJA, Dicke M. Modulation of flavonoid metabolites in Arabidopsis thaliana through overexpression of the MYB75 transcription factor: role of kaempferol-3,7-dirhamnoside in resistance to the specialist insect herbivore Pieris brassicae. J Exp. Bot. 2014; 65:2203-17.

4. Machado RA, McClure M, Hervé MR, Baldwin IT, Erb M. Benefits of jasmonate-dependent defenses against vertebrate herbivores in nature. eLife, 2016; 5:e13-720.

5. Steppuhn A, Gase K, Krock B, Halitschke R, Baldwin IT. Nicotine's defensive function in nature. PLOS Biol. 2016; 2:e2-17.

6. Maag D, Köhler A, Robert CAM, Frey M, Wolfender JL, et al. Highly localized and persistent induction of $\mathrm{Bx} 1-$ dependent herbivore resistance factors in maize. Plant $\mathrm{J}$. 2016; 88:976-91.

7. Bleeker PM, Mirabella R, Diergaarde PJ, Vandoorn A, Tissier A et al. Improved herbivore resistance in cultivated tomato with the sesquiterpene biosynthetic pathway from a wild relative. PNAS. 2012; 109:20124-29.

8. Vaughan MM, Wang Q, Webster FX, Kiemle D, Hong YJ et al. Formation of the unusual semivolatile diterpene rhizathalene by the Arabidopsis class I terpene synthase TPS08 in the root stele is involved in defense against belowground herbivory. Plant Cell. 2013; 25:1108-25.

9. Huber M, Epping J, Schulze Gronover C, Fricke J, Aziz Z et al. A latex metabolite benefits plant fitness under root herbivore attack. PLOS Biol. 2016; 14:e100-2332.
10. Barth C, Jander G. Arabidopsis myrosinases TGG1 and TGG2 have redundant function in glucosinolate breakdown and insect defense. Plant J. 2006; 46:549-62.

11. Pfalz M, Vogel H, Kroymann J. The gene controlling the indole glucosinolate modifier1 quantitative trait locus alters indole glucosinolate structures and aphid resistance in Arabidopsis. Plant Cell. 2009; 21:985-99.

12. Kusnierczyk A, Winge P, Jørstad TS, Troczynska J, Rossiter JT, Bones AM. Towards global understanding of plant defence against aphids-timing and dynamics of early Arabidopsis defence responses to cabbage aphid (Brevicoryne brassicae) attack. Plant Cell Environ. 2008; 31:1097-115.

13. Handrick V, Robert CAM, Ahern KR, Zhou S, Machado RAR et al. Biosynthesis of 8-Omethylated benzoxazinoid defense compounds in maize. Plant Cell. 2016; 28:1682700.

14. Johnson R, Narvaez J, An G, Ryan C. Expression of proteinase inhibitors $I$ and II in transgenic tobacco plants: effects on natural defense against Manduca sexta larvae. PNAS. 1989; 86:9871-75.

15. Pechan T, Cohen A, Williams WP, Luthe DS. Insect feeding mobilizes a unique plant defense protease that disrupts the peritrophic matrix of caterpillars. PNAS. 2002; 99:13319-23.

16. Gonzales-Vigil E, Bianchetti CM, Phillips GN, Howe GA. Adaptive evolution of threonine deaminase in plant defense against insect herbivores. PNAS. 2011; 108:5897902.

17. Chen H, Wilkerson CG, Kuchar JA, Phinney BS, Howe GA. Jasmonate-inducible plant enzymes degrade essential amino acids in the herbivore midgut. PNAS. 2005; 102:19237-42.

18. Kang JH, Wang L, Giri A, Baldwin IT. Silencing threonine deaminase and JAR4 in Nicotiana attenuata impairs jasmonic acid-isoleucine-mediated defenses against Manduca sexta. Plant Cell. 2006; 18:3303-20.

19. Zhang C, Shi H, Chen L, Wang X, Lü B et al. Harpininduced expression and transgenic overexpression of the phloem protein gene AtPP2-A1 in Arabidopsis repress phloem feeding of the green peach aphid Myzus persicae. BMC Plant Biol. 2011; 11:11.

20. Kloth KJ, Busscher-Lange J, Wiegers GL, Kruijer W, Buijs $\mathrm{G}$ et al. Sieve Element-Lining Chaperone1 restricts aphid feeding on Arabidopsis during heat stress. Plant Cell. 2017; 29:2450-64.

21. Shiojiri K, Kishimoto K, Ozawa R, Kugimiya S, Urashimo $\mathrm{S}$ et al. Changing green leaf volatile biosynthesis in plants: an approach for improving plant resistance against both herbivores and pathogens. PNAS. 2006; 103:16672-76.

22. Halitschke R, Stenberg JA, Kessler D, Kessler A, Baldwin IT. Shared signals-"alarm calls" from plants increase apparency to herbivores and their enemies in nature. Ecol. Lett. 2008; 11:24-34.

23. Schuman MC, Barthel K, Baldwin IT. Herbivory-induced volatiles function as defenses increasing fitness of the native plant Nicotiana attenuata in nature. eLife. 2012; 1:e00-007.

24. Schnee C, Köllner TG, Held M, Turlings TCJ, Gershenzon J, Degenhardt J. The products of a single maize sesquiterpene synthase form a volatile defense signal that attracts natural enemies of maize herbivores. PNAS. 2006; 103:1129-34. 
25. Li S, Wang H, Li F, Chen Z, Li X et al. The maize transcription factor EREB58 mediates the jasmonateinduced production of sesquiterpene volatiles. Plant $\mathrm{J}$. 2015; 84:296-308.

26. Xiao Y, Wang Q, Erb M, Turlings TCJ, Ge L et al. Specific herbivore-induced volatiles defend plants and determine insect community composition in the field. Ecol. Lett. 2012; 15:1130-39.

27. Kivimäki M, Kärkkäinen K, Gaudeul M, Løe G, Agren J. Gene, phenotype and function: GLABROUS1 and resistance to herbivory in natural populations of Arabidopsis lyrata. Mol. Ecol. 2007; 16:453-62.

28. Reymond P, Bodenhausen N, Van Poecke RMP, Krishnamurthy V, Dicke M, Farmer EE. A conserved transcript pattern in response to a specialist and a generalist herbivore. Plant Cell. 2004; 16:3132-47.

29. Blanc C, Coluccia F, L'Haridon F, Torres M, OrtizBerrocal $\mathrm{M}$ et al. The cuticle mutant eca2 modifies plant defense responses to biotrophic and necrotrophic pathogens and herbivory insects. Mol. Plant-Microbe Interact. 2018; 31:344-55.

30. Machado RAR, Ferrieri AP, Robert CAM, Glauser G, Kallenbach $\mathrm{M}$ et al. Leaf-herbivore attack reduces carbon reserves and regrowth from the roots via jasmonate and auxin signaling. New Phytol. 2013; 200:1234-46.

31. Machado RAR, Zhou W, Ferrieri AP, Arce CCM, Baldwin IT et al. Species-specific regulation of herbivoryinduced defoliation tolerance is associated with jasmonate inducibility. Ecol. Evol. 2017; 7:3703-12.

32. Schwachtje J, Minchin PEH, Jahnke S, Van Dongen JT, Schittko U, Baldwin IT. SNF1 related kinases allow plants to tolerate herbivory by allocating carbon to roots. PNAS. 2006; 103:12935-40.

33. Schweizer F, Bodenhausen N, Lassueur S, Masclaux FG, Reymond P. Differential contribution of transcription factors to Arabidopsis thaliana defense against Spodoptera littoralis. Front. Plant Sci. 2013; 4:13.

34. Brachi B, Meyer CG, Villoutreix R, Platt A, Morton T et al. Coselected genes determine adaptive variation in herbivore resistance throughout the native range of Arabidopsis thaliana. PNAS. 2015; 112:4032-37.

35. Chan EKF, Rowe HC, Corwin JA, Joseph B, Kliebenstein DJ. Combining genome-wide association mapping and transcriptional networks to identify novel genes controlling glucosinolates in Arabidopsis thaliana. PLOS Biol. 2011; 8:e100-1125. 